\title{
P-PORT INDEX: UMA MEDIDA BASEADA EM PRINCÍPIOS LINGUÍSTICOS PARA ANÁLISE DA FACILIDADE DE LEITURA DE RELATÓRIOS FINANCEIROS
}

\section{P-PORT INDEX: A MEASUREMENT BASED ON LINGUISTIC PRINCIPLES FOR THE ANALYSIS OF THE FINANCIAL REPORTS READABILITY \\ P-PORT INDEX: UNA MEDIDA BASADA EN PRINCIPIOS LINGÜÍSTICOS PARA EL ANÁLISIS DE LA LEGIBILIDAD DE LOS INFORMES FINANCEIROS}

Recebido em: 31-07-2019

Avaliado em: 05-04-2020

Reformulado em: 17-04-2020

Aceito para publicação em: 28-04-2020

Publicado em: 02-09-2020

Editor Responsável: Tarcísio Pedro da Silva
Fernanda Francielle de Oliveira Malaquias ${ }^{1}$

Carolina Coelho da Silveira ${ }^{2}$

\section{RESUMO}

Tendo em vista a necessidade de uma comunicação clara e compreensível com os investidores, a U.S. Securities and Exchange Commission tem incentivado a escrita de relatórios em uma forma simplificada do inglês, conhecida como Plain English. Essa demanda tem reflexo no cenário brasileiro, pois relatórios escritos em português também precisam ser de fácil compreensão. Percebese, dessa forma, a necessidade de se investigar aspectos relacionados à língua portuguesa que podem interferir na legibilidade dos relatórios publicados pelas empresas brasileiras. Nesse contexto, esse artigo tem como objetivo principal propor uma medida baseada em aspectos linguísticos para avaliar o nível de facilidade de leitura de relatórios escritos em português. Considerando a medida proposta, foi avaliado o nível de legibilidade dos Relatórios da Administração publicados pelas empresas listadas no Índice Brasil 50 (IBrX-50). Os principais resultados evidenciam a presença e a frequência de ocorrência de aspectos linguísticos que podem prejudicar a compreensão dos relatórios pelos usuários externos da informação contábil. Como principal contribuição do estudo, destaca-se a proposta de uma nova medida para a mensuração da legibilidade de relatórios, denominada $P$-PORT Index.

Palavras-chave: Disclosure; Legibilidade; Linguística.

\section{ABSTRACT}

Considering the need for a clear and understandable communication with investors, the U.S. Securities and Exchange Commission has encouraged the writing of reports in a simplified form of English, known as Plain English. This demand is also reflected in other markets, such as the Brazilian case, as reports written in Brazilian Portuguese also need to be easy to understand. Therefore, we can realize the need to investigate aspects related to the Portuguese language that may affect the

\footnotetext{
${ }^{1}$ Doutorado em Engenharia Elétrica pela Universidade Federal de Uberlândia (UFU); Professor do Programa de PósGraduação em Administração da Universidade Federal de Uberlândia (UFU); E-mail: fernandafrancielle@gmail.com

2 Graduanda do Curso de Administração da Universidade Federal de Uberlândia (UFU); E-mail: carolinasilveira004@gmail.com
} 
readability of reports published by Brazilian companies. In this context, the aim of this paper is to propose a measure based on linguistic aspects to evaluate the level of readability of reports written in Portuguese. Using the proposed measure, we evaluated the level of readability of the Management Reports published by the companies listed in the Brazil 50 Index (IBrX-50). The main results show the presence and frequency of linguistic aspects that may impair the understanding of reports by external users of accounting information. As the main contribution of this study, we highlight the proposal of a new measure to evaluate the readability of reports, called P-PORT Index.

Palavras-chave: Disclosure; Readability; Linguistics.

\section{RESUMEN}

En vista de la necesidad de una comunicación clara y comprensible con los inversores, la Comisión de Bolsa y Valores de los Estados Unidos ha alentado la redacción de informes en una forma simplificada de inglés, conocida como Plain English. Esta demanda se refleja en otros mercados, como Brasil, ya que los informes escritos en portugués también deben ser fáciles de entender. Por lo tanto, se percibe la necesidad de investigar aspectos relacionados con el idioma portugués que pueden interferir en la legibilidad de los informes publicados por las empresas brasileñas. En este contexto, este artículo tiene como objetivo proponer una medida basada en aspectos lingüísticos para evaluar el nivel de legibilidad de los informes financieros escritos en portugués. Considerando la medida propuesta, se evaluó el nivel de legibilidad de los Informes publicados por las empresas que figuran en el Índice Brasil 50 (IBrX-50). Los principales resultados muestran la presencia y frecuencia de la aparición de aspectos lingüísticos que pueden dañar la comprensión de los informes por parte de los usuarios externos de la información contable. Como principal contribución del estudio, destacamos la propuesta de una nueva medida para la legibilidad de los informes, denominada Índice P-PORT.

Palabras clave: Divulgación; Legibilidad; Lingüística.

\section{INTRODUÇÃO}

Diversas pesquisas em Contabilidade e Finanças têm destacado a relevância da evidenciação de informações pelas empresas, sob o argumento de que um maior nível de informações pode reduzir a percepção de riscos e a incerteza, reduzir a assimetria de informações e os custos de transação para investidores (Bauman, \& Nier, 2004; Richardson, \& Welker, 2001; Schoenfeld, 2017). Entretanto, para que se tenha uma comunicação efetiva com analistas e investidores, é importante que as informações sejam evidenciadas de maneira compreensível, concisa e transparente (Richardson, \& Welker, 2001; Xu, Guy, \& Tam, 2018). A evidenciação pode ser vista como o ato de divulgar informações de forma clara, o que vai além de simplesmente divulgar algo (Aquino, \& Santana, 1992).

Conforme apontado por Lo, Ramos e Rogo (2017), como a narrativa textual corresponde a cerca de $80 \%$ dos relatórios anuais (o restante corresponde a números), a clareza dessa parte textual é fundamental para que o relatório possa ser entendido e interpretado corretamente. A ordenação e clareza das informações contábeis contribuem, assim, para que a contabilidade auxilie no processo de tomada de decisão (Dias Filho, 2000). Nesse sentido, como uma agência regulamentadora, a U.S. Securities and Exchange Commission - SEC tem promovido iniciativas como a Plain Writing Act e publicou um guia sobre como se comunicar com os investidores de maneira mais clara, por meio de uma forma simplificada do inglês denominada Plain English (SEC, 1998; SEC, 2019). O guia publicado pela SEC aponta itens tais como sentenças longas, voz passiva, uso de jargões, sentenças negativas, verbos fracos, palavras abstratas, palavras supérfluas, dentre outros, que tornam os textos menos legíveis e que são problemas comuns encontrados em relatórios (SEC, 1998; Hwang, \& Kim, 2017). 
Inspirada pelo guia publicado pela SEC, em 2019 a Comissão de Valores Mobiliários (CVM) publicou orientações para redação de ofertas públicas de valores mobiliários. As orientações da CVM representam iniciativas no cenário brasileiro buscando a emissão de relatórios financeiros que apresentem maior facilidade de leitura para os usuários externos. Dentre as orientações, tem-se que:

\begin{abstract}
Os investidores precisam ler e compreender os documentos de divulgação de ofertas para se beneficiar plenamente das proteções oferecidas pelas nossas Instruções. Como muitos deles não são advogados, contadores, economistas ou analistas de investimento, os documentos de divulgação devem ser escritos em uma linguagem que os investidores possam entender. Deve-se questionar se os documentos dão destaque para as informações importantes que os investidores precisam para tomar decisões. O "juridiquês", o "economês" e demais jargões do passado devem dar lugar a palavras cotidianas que comunicam informações complexas claramente (CVM, 2019, p. 48).
\end{abstract}

Devido à importância da facilidade de leitura dos relatórios financeiros, várias pesquisas sobre o tema foram realizadas nos últimos anos, sendo que as medidas utilizadas para mensurar a facilidade de leitura dos relatórios, geralmente, consideram o comprimento das sentenças, o tamanho das palavras ou o tamanho dos arquivos (em megabytes) (Loughran, \& Mcdonald, 2014; Rodrigues, \& Silva, 2015; Lahtinen, \& Shipe, 2017; Lo, Ramos, \& Rogo, 2017; Bonsal IV et al., 2017).

Um exemplo de índice utilizado para analisar a facilidade de leitura é o índice de Fog que combina o tamanho das sentenças com a proporção de palavras complexas (palavras com mais de duas sílabas) (Loughran, \& Mcdonald, 2014). Embora esse índice seja bem aceito como medida de legibilidade, Loughran e McDonald (2014), apontam como uma de suas limitações para análise de relatórios financeiros o fato de considerar como complexa qualquer palavra com mais de duas sílabas, mesmo quando ela apresenta um significado fácil de ser entendido por investidores. Além disso, a presença de sentenças longas é apenas um dos problemas linguísticos que, de acordo com o guia sobre Plain English da SEC, dificultam a leitura de textos.

Visando analisar outros problemas linguísticos apontados no guia da SEC e capturar melhor os atributos do Plain English, Hwang e Kim (2017) e Bonsal IV et al. (2017) propuseram novas medidas para analisar a facilidade de leitura de relatórios. Os autores desses estudos validaram os índices propostos e concluíram que eles são mais refinados e refletem melhor o nível de facilidade de leitura dos documentos que os índices baseados apenas no tamanho das sentenças, palavras ou arquivos (Hwang, \& Kim, 2017; Bonsal IV et al., 2017). Os dois referidos estudos, em conjunto com o guia sobre a Plain English da SEC, motivaram a realização desta pesquisa no cenário brasileiro.

Considerando a relevância do nível de evidenciação, e mais especificamente da facilidade de leitura das informações evidenciadas, esse artigo tem como objetivo principal propor uma medida baseada em aspectos linguísticos para avaliar o nível de facilidade de leitura de relatórios escritos em português. Dentre esses aspectos estão a presença de anáforas, catáforas, negativas duplas, voz passiva, palavras e termos desconhecidos, sentenças complexas, vocabulário vago, rebuscado ou incorreto, que dependendo da forma como são utilizados, podem comprometer a legibilidade de textos (Liberato, \& Fulgêncio, 2007). Como objetivo secundário, pretende-se analisar o nível de facilidade de leitura dos relatórios da Administração publicados pelas empresas listadas na BM\&FBovespa (atual $[\mathrm{B}]^{3}$ ) considerando a medida proposta.

Do ponto de vista prático, o estudo identifica aspectos linguísticos que podem ser evitados pelos gestores na escrita de relatórios. Do ponto de vista teórico, o estudo representa um avanço na literatura sobre evidenciação ao propor uma nova medida para mensurar a facilidade de leitura de relatórios escritos em português.

Ressalta-se que no contexto brasileiro, realizamos um levantamento em periódicos nacionais e internacionais e não identificamos nenhum estudo que considerou aspectos linguísticos para analisar a legibilidade de relatórios escritos em português. O único estudo encontrado que analisou outros aspectos linguísticos que podem interferir na legibilidade de relatórios, além do tamanho das sentenças e das palavras, foi o de Peleias (2017). O estudo teve como objetivo identificar a presença 
de mecanismos linguísticos favoráveis e desfavoráveis (relacionados à coesão e coerência) nas demonstrações financeiras, sendo que uma das limitações apontadas pela autora foi o uso de uma amostra restrita composta por apenas seis empresas (Peleias, 2017). Dessa forma, parece haver uma carência de estudos que visem propor medidas de legibilidade de relatórios escritos em português baseadas em aspectos linguísticos, especialmente considerando o alinhamento das recomendações da CVM e da SEC sobre facilidade de leitura de documentos.

A presente pesquisa avança em relação aos demais estudos citados nesta introdução, especialmente pela proposta de um índice baseado em princípios linguísticos apontados por Liberato e Fulgêncio (2007), que pode ser aplicado a relatórios escritos em português. Além disso, foram analisados os relatórios de todas as empresas listadas no IBrX-50 com base neste índice, o que permitiu identificar os problemas mais frequentes e testar se relatórios maiores apresentam maior frequência desses problemas.

\section{REVISÃO DA LITERATURA}

O efeito da informação contábil no mercado de ações tem sido objeto de pesquisa desde a década de 1960. Por exemplo, podemos citar o artigo de Ball e Brown (1968), no qual os autores analisaram o efeito que o resultado publicado pelas empresas (lucro / prejuízo) apresenta nas ações negociadas por elas no mercado financeiro. Várias outras pesquisas também abordam os possíveis efeitos da informação contábil ou dos indicadores econômico-financeiros obtidos por meio das demonstrações contábeis. Schoenfeld (2017), por exemplo, identificou que o nível de disclosure voluntário afetou a liquidez das ações de uma amostra das empresas listadas no índice S\&P500, enquanto Bauman e Nier (2004) observaram um efeito negativo do nível de disclosure na volatilidade de ações de bancos.

Adicionalmente, há uma corrente de estudos que analisa o conteúdo informacional e os seus aspectos textuais, mais especificamente ligados à qualidade do texto e da redação (por ex: Richardson, \& Welker, 2001; Plumlee et al., 2015; Ajina, Laouiti, \& Msolli, 2016; Luo, Li, \& Chen, 2018), sendo essa a linha de estudos em que a presente pesquisa se encaixa.

O estudo de Wang, Hsieh e Sarkis (2018), teve como objetivo investigar a relação entre a performance da empresa em Responsabilidade Social Corporativa (RSC) e a facilidade de leitura dos relatórios de RSC. Os resultados mostraram que empresas com melhor desempenho em RSC tendem a ter relatórios mais legíveis. Já Ajina, Laouiti e Msolli (2016), examinaram a relação entre a legibilidade dos relatórios anuais e o gerenciamento de resultados e concluíram que empresas que utilizam técnicas de gerenciamento de resultados são mais propensas a aumentar a complexidade dos relatórios, comprometendo, assim, a sua legibilidade.

Segundo Guay, Samuels e Taylor (2016), a complexidade dos relatórios financeiros pode afetar negativamente o ambiente informacional, dificultando a internalização de informações por parte de investidores tanto profissionais quanto não profissionais. Além disso, de acordo com Xu, Fernando e Tam (2018) a literatura tem relacionado a complexidade dos relatórios com a intenção de ofuscar uma baixa performance.

Bai, Dong e Hu (2019) enfatizam que há um custo de processamento da informação relacionado à legibilidade de textos, que pode impactar na sincronização futura do retorno das ações das empresas com o retorno do mercado. Conforme apontado por Luo, Li e Chen (2018), como os relatórios anuais são as principais fontes de informação para a tomada de decisão dos investidores externos, a falta de legibilidade desses relatórios pode implicar em maiores custos de agência.

No Brasil, uma medida comumente usada em estudos relacionados à legibilidade de relatórios financeiros é o método de Flesch, um tradicional índice usado para estimação da facilidade de leitura de textos, que considera o tamanho das sentenças, dos parágrafos e das palavras (medido pela quantidade de sílabas) (Rodrigues, \& Silva; 2015; Bernardes et al., 2018). Entretanto, além dos tamanhos das sentenças e das palavras, outros problemas linguísticos também podem dificultar a 
leitura dos relatórios (Bonsal IV et al., 2017; Hwang, \& Kim, 2017). Assim, recentemente pesquisadores tem voltado sua atenção para esses problemas, buscando propor novas medidas para analisar a facilidade de leitura de relatórios financeiros com base nos atributos do Plain English, o que é o caso das pesquisas de Hwang e Kim (2017) e de Bonsal IV et al. (2017).

Considerando a necessidade de uma escrita compreensível em todas as atividades profissionais, Liberato e Fulgêncio (2007) publicaram um guia sobre como escrever de forma clara. Neste guia, são apresentados princípios que podem interferir na legibilidade de textos escritos em português, semelhante ao que foi feito no guia publicado pela SEC. Para esta pesquisa, esses princípios foram agrupados em 6 categorias e estão listados no Apêndice A. Com base nesses princípios e em consonância com o estudo de Hwang e Kim (2017), o presente estudo pretende propor uma medida para a facilidade de leitura de relatórios publicados em português pelas empresas brasileiras.

\section{METODOLOGIA}

Para atingir o objetivo geral dessa pesquisa, consideramos na composição da amostra do estudo as empresas listadas no Índice Brasil 50 ( $\mathrm{IBrX}-50)$, que contempla os 50 ativos de maior negociabilidade e representatividade do mercado de ações brasileiro (B3, 2018). Coletamos os dados em 2018 por meio dos relatórios da Administração publicados pelas 49 empresas da amostra relativos ao ano de 2017. Destaca-se que estes dados são públicos no sítio eletrônico da $[\mathrm{B}]^{3}$.

Para facilitar a análise, salvamos os relatórios no computador e os convertemos em arquivos *.doc. Em seguida, excluímos Tabelas, sumários, figuras e gráficos. Após essa exclusão, observamos que três empresas apresentaram relatórios com mais de 50 páginas. Optamos por excluir essas três empresas da amostra e para as outras 46 empresas, fizemos a leitura e analisamos todas as páginas dos relatórios.

Para análise da facilidade de leitura dos relatórios, seguimos os princípios relacionados à legibilidade de textos apresentados por Liberato e Fulgêncio (2007), os quais foram agrupados em 6 categorias conforme apresentado no Apêndice A. Assim como em Hwang e Kim (2017), não levamos em consideração a categoria que se refere à estrutura do relatório para cálculo do índice de legibilidade. Entretanto, por ser um elemento que pode melhorar a legibilidade de textos, consideramos o fato de o texto estar ou não dividido em tópicos na análise descritiva.

Por envolver questões subjetivas, também não levamos em consideração a categoria referente ao conhecimento prévio dos leitores na análise. Assim, consideramos para cálculo do índice de legibilidade os princípios de apenas 4 categorias, sendo elas: Anáforas, Catáforas, Vocabulário e Estrutura. O Apêndice A apresenta maiores detalhes relativos a cada uma destas categorias.

Examinamos os relatórios parágrafo por parágrafo de forma manual (sem auxílio de softwares), o que permitiu identificar e contabilizar problemas linguísticos que podem comprometer a facilidade de leitura ao longo de todo o relatório. Sanamos eventuais dúvidas que surgiram durante o processo de análise com uma consultora especializada em linguística.

Com relação aos termos desconhecidos (na categoria de Vocabulário do Apêndice A), contabilizamos aqueles com os quais investidores não profissionais possam não estar familiarizados, tais como termos estrangeiros e jargões. De acordo com as recomendações da CVM (2019) e da SEC (1998), jargões devem ser evitados para não comprometer a compreensão do texto por parte desses investidores. Nesta categoria também se enquadram palavras ou termos incorretos ou de sentido abstrato. Para a análise quantitativa, esta variável que denominamos: "Pal./Termos Incorr., Desc., ou Sent. Abstr.", indica a frequência com a qual essas palavras e termos apareceram durante a análise dos relatórios.

No que se refere ao cumprimento das sentenças, de acordo com Hwang e Kim (2017) e Liberato e Fulgêncio (2007), não existe uma definição objetiva do que seja uma sentença longa. Dessa forma, não contabilizamos as sentenças longas assim como em Hwang e Kim (2017). Segundo 
Liberato e Fulgêncio (2007), o comprimento excessivo de uma sentença não é o maior problema, mas sim as características dele decorrentes. Dentre essas características estão a complexidade da estrutura interna da sentença, as inserções e a organização de várias ideias em uma mesma sentença, o que levamos em consideração para classificar as sentenças como complexas ou não complexas (Liberato, \& Fulgêncio, 2007). Assim, a variável "Sentenças Complexas" (dentro da categoria de Estrutura do Apêndice A) indica a frequência de sentenças que possuem complexidade em sua estrutura interna, inserções ou organização de várias ideias. Ainda na categoria de Estrutura, consideramos as frequências de "Negativas Duplas" e de "Estruturas Passivas", conforme também está disponível no Apêndice A.

Sobre as anáforas (termos que retomam uma ideia mencionada anteriormente no texto), é importante destacar que a simples presença delas pode não constituir dificuldade de leitura (Liberato, \& Fulgêncio, 2007). Desta forma, foram contabilizadas apenas as anáforas dos tipos listados na categoria Anáforas do Apêndice A. Com relação às catáforas, Liberato e Fulgêncio (2007) as definem como expressões que remetem a um referente que será introduzido posteriormente no texto. Segundo as autoras, quanto mais distante a catáfora estiver do seu referente, mais difícil será a sua interpretação. Na análise, consideramos no cálculo de frequência da categoria Catáforas do Apêndice A todas as sentenças que contém catáforas ou que contém expressões com valor catafórico.

Em síntese, as quatro categorias que fazem parte do índice reúnem seis diferentes variáveis, sendo elas:

- Categoria Anáforas (com a quantidade de anáforas conforme Apêndice A);

- Categoria Catáforas (com a quantidade de catáforas ou de expressões com valor catafórico);

- Categoria Vocabulário (com a quantidade de termos estrangeiros, jargões, palavras ou termos incorretos ou de sentido abstrato);

- Categoria Estrutura (com a quantidade de sentenças que possuem complexidade em sua estrutura interna ou organização de várias ideias, quantidade de negativas duplas e de estruturas passivas).

Com base nos itens relacionados às quatro categorias mencionadas, a cada empresa da amostra atribuímos um indicador para facilidade de leitura, denominado P-PORT index, que pondera a frequência observada nas quatro categorias pelo número de sentenças do respectivo relatório. Em consonância com Hwang e Kim (2017), a medida P-PORT index (referente a plain Portuguese index) utilizada para mensurar o nível de legibilidade dos relatórios, é definida como:

$$
\text { P_PORT index }=\frac{(\text { \#anáforas }+ \text { \#catáforas }+ \text { \#vocabulário }+ \text { \#estrutura }) * 100}{\text { \#sentenças }}
$$

O índice considera uma ponderação pela quantidade de sentenças, representando assim uma medida relativa da quantidade de problemas linguísticos frente ao tamanho do relatório. Conforme enfatizado por Hwang e Kim (2017, p. 378), embora a medida aqui proposta "não conte diretamente o número de "sentenças longas" em um documento (dado que falta uma definição objetiva do que constitui uma sentença longa), a ponderação pelo número de sentenças indiretamente captura o comprimento das sentenças". Diferentemente de Hwang e Kim (2017), optamos por não multiplicar o índice por -1 e por multiplicá-lo por 100. Assim, relatórios que apresentam mais problemas linguísticos recebem maiores scores.

Após a obtenção dos indicadores, elaboramos tabelas com a estatística descritiva desses indicadores da amostra como um todo e segregados por setor de atividade, o que permitiu evidenciar um panorama a respeito da facilidade de leitura dos relatórios publicados pelas empresas analisadas. Também realizamos uma análise para testar uma possível relação entre o tamanho dos relatórios e o $P$-PORT index, com o objetivo de verificar se relatórios maiores possuem maiores scores. Para tanto, empregamos a análise de correlação por postos de Spearman (Hair Jr. et al., 2011). 


\section{ANÁLISE DOS RESULTADOS}

A Tabela 1 evidencia a estatística descritiva relativa aos problemas linguísticos encontrados nos relatórios, mostrando também a sua análise por quartis. Por exemplo, observamos na Tabela 1 que $50 \%$ das empresas apresentaram pelo menos 23 catáforas ou expressões com função catafórica em seus relatórios (dado que a mediana para esta variável foi igual a 23; assim, metade das empresas possui menos de 23 catáforas e a outra metade, mais de 23 catáforas).

O Apêndice B mostra exemplos desses problemas linguísticos encontrados. A divisão dos relatórios em tópicos não foi considerada no cálculo do índice de legibilidade, mas uma análise desse item mostrou que, dos 46 relatórios, apenas 2 não estão divididos em tópicos (foram atribuídos os valores 1 para relatórios que estavam divididos em tópicos e 0 para os demais). Destaca-se que a divisão em tópicos também é um dos elementos que podem facilitar a leitura dos textos.

Tabela 1: Estatística Descritiva para os Problemas Linguísticos Encontrados nos Relatórios

\begin{tabular}{|c|c|c|c|c|c|c|c|}
\hline $\begin{array}{l}\text { Categorias } \\
\text { (Apênd. A) }\end{array}$ & Variáveis & $\mathbf{N}$ & Mín. & $\begin{array}{c}\text { Q1 } \\
(25 \%)\end{array}$ & $\begin{array}{c}\text { Q2 } \\
(50 \%)\end{array}$ & $\begin{array}{c}\text { Q3 } \\
(75 \%)\end{array}$ & Máx. \\
\hline--- & Número de Sentenças & 46 & 29 & 172 & 230 & 346 & 663 \\
\hline Tópicos & Divisão em Tópicos (variável dummy) & 46 & 0 & 1 & 1 & 1 & 1 \\
\hline Anáforas & Anáforas & 46 & 0 & 2 & 3 & 4 & 11 \\
\hline Catáforas & Catáforas & 46 & 2 & 14 & 19 & 35 & 98 \\
\hline Vocabulário & Pal./Termos Incorr., Desconh., ou Sent. Abstr. & 46 & 0 & 5 & 10 & 13 & 53 \\
\hline Estrutura & Sentenças Complexas & 46 & 0 & 5 & 11 & 17 & 66 \\
\hline Estrutura & Negativa Dupla & 46 & 0 & 0 & 1 & 2 & 4 \\
\hline Estrutura & Voz Passiva & 46 & 4 & 37 & 69 & 115 & 316 \\
\hline
\end{tabular}

Notas: As categorias apresentadas na tabela referem-se às mesmas categorias disponíveis com maiores detalhes no Apêndice A; Divisão em Tópicos = é uma variável dummy que recebe 1 para empresas que utilizaram a divisão de tópicos em seus relatórios; Anáforas = indica a frequência de anáforas no relatório analisado; Catáforas $=$ indica a frequência de catáforas (ou expressões com função catafórica) no relatório analisado; Sentenças Complexas = indica o número de sentenças complexas no relatório analisado; Negativa Dupla = indica a frequência de negativas duplas no relatório analisado; Voz Passiva = indica a frequência de voz passiva no relatório analisado; Pal./Termos Incorr., Desc., ou Sent. Abstr. = indica a quantidade de ocorrências de Palavras / Termos Incorretos, Desconhecidos ou Sentenças Abstratas; Número de Sentenças = número de sentenças do relatório analisado.

A Tabela 1 mostra que todo relatório consultado possui pelo menos 2 catáforas (valor mínimo da variável catáforas na Tabela 1). As catáforas ou expressões com valor catafórico são elementos que podem prejudicar a leitura de textos, especialmente quando o seu referente está distante (Liberato, \& Fulgêncio, 2007). Assim, tendo em vista que todos os relatórios consultados possuem pelo menos duas sentenças que apresentam catáforas e que metade dos relatórios possui pelo menos 19 catáforas, os gestores poderiam ampliar esforços para evitar esse tipo de problema linguístico, facilitando a leitura dos relatórios para os usuários da informação contábil.

Os resultados mostram que existe na amostra pelo menos um relatório sem ocorrência de problemas linguísticos relacionados ao vocabulário (Palavras / Termos Incorretos, Palavras / Termos Desconhecidos ou Sentenças Abstratas). Entretanto, metade das empresas analisadas possui entre 10 e 53 problemas de vocabulário, o que também desfavorece a transmissão de uma mensagem clara pela empresa aos usuários dos relatórios. Por outro lado, as estatísticas relativas à negativa dupla indicam que este problema linguístico possui baixa frequência nos relatórios. O valor máximo para negativas duplas foram quatro. Ademais, a análise mostrou que $75 \%$ dos relatórios possui duas ou menos negativas duplas em seu conteúdo.

Adicionalmente, conforme resultados da Tabela 1, entre as variáveis com maior mediana estão o uso de voz passiva e de catáforas, elementos estes que podem dificultar a leitura dos relatórios financeiros, como apontado anteriormente. Os relatórios das empresas apresentaram voz passiva em trechos relativos à rentabilidade, crescimento da receita, realização de reuniões, ações / iniciativas da empresa, contratação de auditores, composição da despesa, dentre outros. O Apêndice 2 contém 
exemplos adicionais com trechos completos de uso de voz passiva pelas empresas. À luz dos estudos sobre evidenciação contábil (por exemplo: Aquino, \& Santana, 1992; Dias Filho, 2000), este artigo evidencia elementos que podem contribuir para que a divulgação das informações seja realizada de forma mais ordenada e clara, de forma que a comunicação da empresa seja melhor compreendida pelas partes interessadas.

A comparação de dois valores presentes na Tabela 1 chama a atenção: o terceiro quartil (Q3 igual a 115) e o valor máximo (Máximo igual a 316) para a contagem de voz passiva. Podemos observar que há elevada distância (e dispersão) no que se refere à presença de voz passiva nos relatórios. Observarmos o relatório da empresa com valor máximo de 316 e notamos o uso de voz passiva para falar sobre investimentos, melhorias, perdas, desperdício, ações sociais, ações ambientais, legislação, dentre vários outros itens. A empresa em questão não necessariamente fez o uso de voz passiva no intuito de tornar uma informação mais difícil de ser compreendida, tendo em vista que identificamos vários trechos que favorecem a imagem da empresa, como práticas de responsabilidade social corporativa. Reforçamos assim nossos argumentos de que a eliminação desses problemas linguísticos pode contribuir com a divulgação das empresas, fazendo com que a mensagem chegue de maneira mais clara para os usuários externos.

A presença de sentenças complexas também é um item com frequência elevada (metade das empresas da amostra possui pelo menos 11 sentenças complexas em seus relatórios). O valor máximo para a variável sentenças complexas é de 66, indicando que metade das empresas possui entre $11 \mathrm{e}$ 66 sentenças complexas nos relatórios anuais consultados. Considerando que as informações fornecidas pelas empresas em seus relatórios anuais são relevantes para tomadores de decisões (Bauman, \& Nier, 2004; Richardson, \& Welker, 2001; Schoenfeld, 2017), o uso de sentenças complexas pode gerar algum efeito nas tomadas de decisão. Ademais, considerando-se que as informações fornecidas pelas empresas devem ser compreensíveis, concisas e transparentes (Richardson, \& Welker, 2001; Xu, Guy, \& Tam, 2018), o uso de sentenças complexas desfavorece a prática de informações concisas.

Desta forma, tem-se um panorama de itens que podem tornar os relatórios publicados pelas empresas mais difíceis de serem lidos. Estes itens deveriam ser evitados pelos elaboradores das demonstrações financeiras. A redução de termos e expressões que se enquadrem como anáforas, catáforas, sentenças complexas, negativa dupla, voz passiva, bem como termos incorretos, desconhecidos ou de sentido abstrato, pode auxiliar também na redução de assimetria informacional entre investidores e gestores. Com a redução (ou mesmo com a eliminação) destes itens, os investidores terão melhores condições de compreender as informações divulgadas pelas empresas.

A Tabela 2 resume a estatística descritiva do P-PORT Index. O valor médio observado (de 52,401 ) indica que as empresas, em média, apresentam uma considerável frequência de problemas linguísticos em seus relatórios. Em outras palavras, a quantidade de problemas linguísticos identificados nos relatórios das empresas corresponde, em média, a mais de $50 \%$ do número de sentenças dos relatórios. O valor máximo indica que existe pelo menos uma empresa que contém nove problemas linguísticos para cada dez sentenças. As empresas podem até ter divulgado as informações de forma tempestiva, mas a presença de problemas linguísticos nos relatórios pode desfavorecer a tomada de decisões também de forma tempestiva.

Tabela 2: Estatística Descritiva para o P-Port Index

\begin{tabular}{cccccc}
\hline Variável & $\mathrm{n}$ & Média & Desv. Pad. & Mín. & Máx. \\
\hline P-Port Index & 46 & 52,401 & 15,433 & 17,155 & 90,517 \\
\hline
\end{tabular}

A Tabela 3 descreve o comportamento médio do P-PORT Index por setor de atividade das empresas componentes da amostra. A Tabela 3 também evidencia a dispersão do P-Port Index por setor de atividades, o que pode ser observando tanto pelo desvio-padrão quanto pelo coeficiente de variação. 
Tabela 3: Média e Desvio-Padrão do P-PORT Index, por setor de atividade

\begin{tabular}{|c|c|c|c|c|}
\hline Setor & $\mathbf{n}$ & $\begin{array}{l}\text { P-Port Index } \\
\text { (Média) }\end{array}$ & $\begin{array}{c}\text { P-Port Index } \\
\text { (Desv. Padrão) }\end{array}$ & $\begin{array}{c}\text { P-Port Index } \\
\text { (Coef. Variação) }\end{array}$ \\
\hline Alimentos e Bebidas & 3 & 44,170 & 10,634 & 24,076 \\
\hline Comércio & 7 & 43,557 & 14,582 & 33,478 \\
\hline Construção & 1 & 38,498 & n.d. & n.d. \\
\hline Energia Elétrica & 2 & 51,472 & 21,669 & 42,098 \\
\hline Finanças e Seguros & 6 & 59,724 & 10,995 & 18,410 \\
\hline Mineração & 1 & 79,032 & n.d. & n.d. \\
\hline Outros & 11 & 51,245 & 14,280 & 27,655 \\
\hline Papel e Celulose & 3 & 63,139 & 14,989 & 23,739 \\
\hline Petróleo e Gás & 2 & 51,245 & 9,983 & 19,481 \\
\hline Química & 1 & 80,361 & n.d. & n.d. \\
\hline Siderurgia e Metalurgia & 4 & 46,279 & 6,862 & 14,827 \\
\hline Software e Dados & 1 & 90,517 & $n . d$. & n.d. \\
\hline Telecomunicações & 1 & 51,124 & n.d. & n.d. \\
\hline Transporte e Serviços & 2 & 35,038 & 8,330 & 23,773 \\
\hline Veículos e Peças & 1 & 57,143 & n.d. & n.d. \\
\hline Total / Média Geral & 46 & 52,401 & 15,433 & 17,155 \\
\hline
\end{tabular}

Notas: $n . d$. = não disponível, em função de se ter apenas uma observação, inviabilizando o cálculo da variabilidade.

Por meio da análise da Tabela 3, observamos que os relatórios de empresas dos setores de Software e Dados, Química, Mineração, Papel e Celulose apresentaram scores mais altos, indicando maiores níveis de dificuldade de leitura. A maior dispersão esteve presente entre os setores de Energia Elétrica e de Comércio, sugerindo certo nível de discricionariedade dos gestores na elaboração dos relatórios. Alguns elaboradores das demonstrações podem preferir o uso de termos mais complexos ou de sentenças mais rebuscadas, enquanto outros podem preferir uma linguagem mais clara e objetiva. Há também o caso de relatórios que são elaborados de maneira mais complexa com um eventual objetivo de tornar mais difícil o entendimento de algum elemento que venha a ser desfavorável para o cenário da empresa (Hwang, \& Kim, 2017; Xu, Fernando, \& Tam, 2018). Contudo, não é possível afirmar que isso ocorreu nos relatórios das empresas da amostra, pois esse tipo de análise não fez parte da proposta desse estudo. Os índices médios mais favoráveis para a leitura dos relatórios foram apresentados pelos setores de Construção e de Transporte e Serviços. Conforme já apontamos anteriormente, elaboramos o Apêndice B de forma a ilustrar alguns exemplos dos itens identificados nos relatórios que tornam o texto menos legível.

Testamos uma possível relação entre o tamanho dos relatórios (medido pelo número de sentenças) e o P-PORT Index, o que permitiu avaliar se relatórios maiores apresentam também menor legibilidade. Para esta análise, empregamos a análise de correlação por postos de Spearman e o coeficiente obtido foi de 0,306 (estatisticamente significativo a 5\%; p =0,038). É importante interpretar esses resultados com cautela, pois a força da associação foi pequena, mas com direção definida (Hair Jr. et al., 2011). O coeficiente positivo e significativo sugere que relatórios com maior número de sentenças tendem também a serem menos legíveis. Assim, investidores e usuários externos da informação financeira publicada pelas empresas, ao se depararem com relatórios extensos, também podem ter uma dificuldade adicional no que se refere à falta de clareza que pode estar presente nos referidos relatórios.

Os principais resultados desta pesquisa revelam que, mesmo com iniciativas para publicação tempestiva das informações financeiras, o conteúdo destas demonstrações, ainda que completo, pode não ser suficiente para mitigar a assimetria de informações. Os resultados indicaram problemas linguísticos que dificultam o entendimento dos relatórios mesmo em trechos em que pode haver 
discricionariedade e subjetividade por parte dos gestores, como no disclosure sobre responsabilidade social corporativa. A falta de clareza na apresentação dos relatórios pode desfavorecer o entendimento adequado das informações ali prestadas. Neste sentido, esta pesquisa contribui ao evidenciar e indicar a frequência de ocorrência de tipos de palavras e expressões que, mesmo nos relatórios mais completos, podem dificultar a compreensão por parte dos usuários externos da informação contábil a respeito da situação econômico/financeira da empresa.

\section{CONSIDERAÇÕES FINAIS}

Por se tratar de um relatório de natureza textual, a facilidade de leitura dos relatórios anuais torna-se fundamental para que as empresas tenham uma comunicação efetiva com analistas e investidores. Assim, essa pesquisa teve como objetivo propor uma medida para análise da facilidade de leitura de relatórios escritos em português.

Primeiramente, identificamos aspectos linguísticos que são comuns em relatórios financeiros e que os gestores podem evitar para não comprometer a legibilidade dos textos. O Apêndice A resume esses aspectos, classificando-os dentro de categorias. Dependendo da forma como são utilizados, elementos tais como anáforas, catáforas e estruturas passivas podem tornar o texto menos legível. O estudo identificou também que não é o fato de uma sentença ter uma grande quantidade de palavras que a torna difícil de ler, mas sim a estrutura complexa ou a organização de muitas ideias em uma mesma sentença.

Após o exame parágrafo a parágrafo dos relatórios, realizado de forma manual (ou seja, sem o auxílio de algum software), identificamos e contabilizamos problemas linguísticos que desfavorecem a facilidade de leitura ao longo do relatório. Os resultados da análise indicaram que a presença de alguns itens como estruturas passivas, termos abstratos, uso de jargões, sentenças longas etc. são problemas comuns que interferem na legibilidade de textos escritos tanto em inglês quanto em português. Por exemplo, observamos que dentre as 46 empresas avaliadas, todos os relatórios possuem pelo menos 2 catáforas. Ademais, metade dos relatórios possui pelo menos 11 sentenças complexas. É relevante, desta forma, que gestores e elaboradores das demonstrações financeiras considerem esses aspectos ao elaborarem as demonstrações financeiras a serem publicadas. Para o caso de empresas listadas no Brasil e no exterior, os gestores devem ainda se lembrar que os aspectos de linguagem que dificultam a leitura se diferem para diferentes línguas, como é o caso do português e inglês.

Os resultados da análise quantitativa sugerem que o tamanho dos relatórios tende a estar associado à sua respectiva facilidade de leitura, indicando que relatórios maiores parecem também apresentar menor legibilidade. O P-PORT index leva em consideração, além do tamanho das sentenças e das palavras, outros aspectos linguísticos que podem prejudicar a compreensão dos relatórios pelos usuários externos da informação contábil. Dessa forma, assim como as medidas propostas nos estudos de Hwang e Kim (2017) e de Bonsal IV et al. (2017), acreditamos que a medida $P$-PORT index pode ser considerada mais refinada e abrangente que outras medidas de legibilidade (como os índices de Fog e de Flesch).

Dentre as limitações da pesquisa é importante ressaltar que os resultados se baseiam na interpretação subjetiva dos pesquisadores que realizaram a análise dos relatórios e que definiram os trechos/sentenças que se enquadravam nas categorias de problemas linguísticos considerados. É oportuno comentar também que algumas sentenças apresentaram mais de um problema linguístico durante a análise dos relatórios e contabilização das frequências.

Esperamos que os resultados do estudo possam contribuir para a escrita de relatórios financeiros que levem em consideração os princípios linguísticos aqui apresentados, de forma a atender às demandas por documentos mais claros e compreensíveis. É oportuno lembrar que esta demanda tem sido observada tanto em nível nacional quanto internacional. Durante a análise dos resultados, observamos problemas linguísticos mesmo em trechos em que haveria vantagem para os 
gestores no uso de uma linguagem mais clara, o que reforça a relevância de se eliminar problemas linguísticos dos relatórios.

Como realizamos a análise do presente trabalho de forma manual, em trabalhos futuros sugerimos o desenvolvimento de um software capaz de realizar as análises de forma automática. Trabalhos futuros também podem analisar os possíveis determinantes da facilidade de leitura dos relatórios considerando o P-PORT index.

\section{REFERÊNCIAS}

Ajina, A., Laouiti, M., \& Msolli, B. (2016). Guiding through the Fog: Does annual report readability reveal earnings management?. Research in International Business and Finance, 38, 509-516.

Aquino, W., \& Santana, A. C. D. (1992). Evidenciação. Caderno de Estudos-FIPECAFI, 5, 1-40.

Bai, X., Dong, Y., \& Hu, N. (2019). Financial report readability and stock return synchronicity. Applied Economics, 51(4), 346-363.

Ball, R., \& Brown, P. (1968). An empirical evaluation of accounting income numbers. Journal of Accounting Research, 6(2), 159-178.

Baumann, U., \& Nier, E. (2004). Disclosure, volatility, and transparency: an empirical investigation into the value of bank disclosure. Economic Policy Review, 10(2), 31-45.

Bernardes, J. R., Nascimento, J. C. H. B. D., Ayres, R. M., \& Siqueira, J. R. M. D. (2018). Legibilidade dos Fatos Relevantes: uma Análise na Vale SA no Período de Agosto 2012 a Agosto de 2016. Pensar Contábil, 20(71).

Bonsall IV, S. B., Leone, A. J., Miller, B. P., \& Rennekamp, K. (2017). A plain English measure of financial reporting readability. Journal of Accounting and Economics, 63(2-3), 329-357.

Comissão de Valores Mobiliários (CVM) (2019). Orientações gerais sobre procedimentos a serem observados pelos emissores e intermediários em ofertas públicas de valores mobiliários. OfícioCircular CVM/SRE No 02/19.

Dias Filho, J. M. (2000). A linguagem utilizada na evidenciação contábil: uma análise de sua compreensibilidade à luz da teoria da comunicação. Caderno de Estudos, 13(24), 38-49.

Guay, W., Samuels, D., \& Taylor, D. (2016). Guiding through the fog: Financial statement complexity and voluntary disclosure. Journal of Accounting and Economics, 62(2-3), 234-269.

Hair Jr., J. F., Celsi, M. W., Money, A. H., Samouel, P., \& Page, M. J. (2011). Essentials of Business Research Methods. 2. ${ }^{a}$ Ed., London: M.E. Sharpe.

Hwang, B. H., \& Kim, H. H. (2017). It pays to write well. Journal of Financial Economics, 124(2), 373-394.

Índice Brasil 50 (IBrX 50). (2018). B3 - BM\&FBovespa.

Lahtinen, K. D., \& Shipe, S. (2017). Readability of financial advisor disclosures. Journal of Empirical Finance, 44, 36-42.

Liberato, Y., Fulgêncio, L., \& Liberato, Y. (2007). É possível facilitar a leitura: um guia para escrever claro. Editora Contexto.

Lo, K., Ramos, F., \& Rogo, R. (2017). Earnings management and annual report readability. Journal of Accounting and Economics, 63(1), 1-25.

Loughran, T., \& McDonald, B. (2014). Measuring readability in financial disclosures. The Journal of Finance, 69(4), 1643-1671.

Luo, J. H., Li, X., \& Chen, H. (2018). Annual report readability and corporate agency costs. China Journal of Accounting Research, 11(3), 187-212.

Peleias, F. D. (2017). Mecanismos linguísticos (des)favoráveis para a readability das demonstrações financeiras: uma análise das empresas listadas no Mercado de capitais brasileiro. Dissertação de Mestrado em Contabilidade, Fundação Escola de Comércio Álvares Penteado, São Paulo.

Plumlee, M., Brown, D., Hayes, R. M., \& Marshall, R. S. (2015). Voluntary environmental disclosure quality and firm value: Further evidence. Journal of Accounting and Public Policy, 34(4), 336-361.

Richardson, A. J., \& Welker, M. (2001). Social disclosure, financial disclosure and the cost of equity capital. Accounting, Organizations and Society, 26(7-8), 597-616.

Rodrigues, F. F., \& Silva, C. A. T. (2015). Determining Factors of the Information Disclosed in the Management Reports of Brazilian Open Companies. Business and Management Review, 4(10), 282298. 
Schoenfeld, J. (2017). The effect of voluntary disclosure on stock liquidity: New evidence from index funds. Journal of Accounting and Economics, 63(1), 51-74.

Securities and Exchange Commission (SEC). (1998). A Plain English Handbook: How to create clear SEC disclosure documents. Washington: Securities and Exchange Commission.

Securities and Exchange Commission (SEC). (2019). Plain Writing Initiative.

Wang, Z., Hsieh, T. S., \& Sarkis, J. (2018). CSR performance and the readability of CSR reports: Too good to be true?. Corporate Social Responsibility and Environmental Management, 25(1), 66-79.

Xu, Q., Fernando, G. D., \& Tam, K. (2018). Executive age and the readability of financial reports. Advances in Accounting, 43, 70-81.

\section{AGRADECIMENTO}

O presente trabalho foi realizado com apoio do Conselho Nacional de Desenvolvimento Científico e Tecnológico $(\mathrm{CNPq})$. 


\section{APÊNDICE A:}

Princípios linguísticos apresentados por Liberato e Fulgêncio (2007)

\begin{tabular}{|c|c|}
\hline Categoria & Princípios \\
\hline $\begin{array}{l}\text { Conhecimento } \\
\text { Prévio }\end{array}$ & $\begin{array}{l}\text { - "Textos cuja compreensão depende da utilização de expectativas fortemente ativadas são } \\
\text { mais legíveis." } \\
\text { - "Textos cuja compreensão depende de conhecimento prévio que o leitor não possui tem a } \\
\text { sua legibilidade comprometida." } \\
\text { - "Elementos dados não marcados podem constituir um fator de dificuldade de leitura." } \\
\text { - "Anáforas cuja interpretação depende de inferências baseadas em conhecimento prévio que } \\
\text { o leitor não possui constituem fator de dificuldade de leitura." }\end{array}$ \\
\hline Tópicos & $\begin{array}{l}\text { - "A dificuldade de identificar o tópico de um texto compromete a sua legibilidade." } \\
\text { - "Para facilitar a leitura, a paragrafação deve refletir a estrutura de tópicos do texto." } \\
\text { - "A informação do as sunto do texto a partir de informações já conhecidas pelo leitor, mesmo } \\
\text { com o consequente des locamento do tópico discursivo da posição inicial, pode facilitar a } \\
\text { leitura." } \\
\text { - "A má sinalização ou a representação inadequada de tópicos compromete a legibilidade de } \\
\text { textos." }\end{array}$ \\
\hline Anáforas & $\begin{array}{l}\text { - "Anáforas com matriz semântica pouco especificada e/ou que dependem de informação } \\
\text { posterior do texto podem constituir dificuldade na leitura, ou mesmo um empecilho à } \\
\text { compreensão." } \\
\text { - "O leitor tende a relacionar elementos anafóricos de uma passagem ao tópico dessa } \\
\text { passagem, mesmo quando certos traços sintáticos ou morfológicos do texto o impediriam em } \\
\text { princípio." } \\
\text { - "Se um texto contém uma anáfora que mantém com seu antecedente uma relação de baixa } \\
\text { frequência conjunta, sua legibilidade será prejudicada." } \\
\text { - "Textos que incluem elementos co-referentes apresentados na ordem específico-genérico são } \\
\text { mais facilmente compreendidos do que aqueles onde a ordem de apresentação é genérico- } \\
\text { específico." }\end{array}$ \\
\hline & - “A presença de catáforas pode dificultar a compreensão dos textos.” \\
\hline Vocabulário & $\begin{array}{l}\text { - "Um texto com alto índice de termos desconhecidos impossibilita a obtenção do significado." } \\
\text { - "O uso de vocabulário vago e rebuscado na construção de um discurso obscuro prejudica a } \\
\text { compreensão dos textos." } \\
\text { - "Palavras conhecidas, mas usadas metaforicamente ou com sentido mais abstrato do que o } \\
\text { corrente, podem constituir um problema para a leitura." } \\
\text { - "O uso de vocabulário incorreto prejudica a leitura e a obtenção da informação." }\end{array}$ \\
\hline \multirow[t]{3}{*}{ Estrutura } & $\begin{array}{l}\text { - "Sentenças muito compridas constituem fator de dificuldade de leitura." } \\
\text { - "Sentenças complexas podem comprometer a legibilidade de um texto." } \\
\text { - "Sequências de organização hierárquica complexa podem reduzir a legibilidade de um texto." } \\
\text { - "Inserções que contém informação relacionada ao tópico da sentença são menos prejudiciais } \\
\text { que aquelas que contém informação relacionada a outros elementos." } \\
\text { - "Elementos sinalizados como tópico têm maior resistência quanto aos efeitos negativos das } \\
\text { inserções." } \\
\text { - "A presença de inserções entre os grandes constituintes da sentença constitui fator de } \\
\text { dificuldade de leitura." }\end{array}$ \\
\hline & $\begin{array}{l}\text { - "Negativas duplas e negativas as sociadas a quantificadores podemprejudicar a legibilidade } \\
\text { dos textos." }\end{array}$ \\
\hline & \\
\hline
\end{tabular}

Fonte: Elaborado com base em Liberato e Fulgêncio (2007). 


\section{APÊNDICE B:}

Exemplos de problemas linguísticos encontrados nos relatórios

\begin{tabular}{|c|c|}
\hline Categoria & Exemplos \\
\hline Anáforas & $\begin{array}{l}\text { "Buscando garantir a equalização da jornada multicanal, na internet modernizamos a plataforma } \\
\text { tecnológica e revis amos a experiência de navegação e compra, tornando -a mais intuitiva para o } \\
\text { usuário". }\end{array}$ \\
\hline Catáforas & $\begin{array}{l}\text { "Para compartilhar conhecimento e ajudar pequenas e médias empresas a economizarem o } \\
\text { recurso, a empresa lançou o SAVEh - Sistema de Autoavaliação de Eficiência Hídrica”. }\end{array}$ \\
\hline \multirow{2}{*}{ Vocabulário } & $\begin{array}{l}\text { Termos desconhecidos, vagos ou com sentido abstrato: } \\
\text { - "Es se montante repres enta um dividend yeld de } 2,4 \$ \text { sobre o preço médio das ações em } 2017 . " \\
\text { - "O resultado orgânico é decorrente do aumento da receita por hectolitro de } 1,5 \%, \\
\text { parcialmente impactado por uma queda de } 1,3 \% \text { no volume de vendas." }\end{array}$ \\
\hline & $\begin{array}{l}\text { Vocabulário incorreto: } \\
\text { - "Além dis so, o índice de alavancagem financeira líquida, calculado pelo soma dos passivos } \\
\text { circulante e não circulante, descontadas as receitas diferida circulante e não circulante, e } \\
\text { dividido pelo patrimônio líquido, atingiu } 0,39 x . "\end{array}$ \\
\hline \multirow{5}{*}{ Estrutura } & Sentenças complexas: \\
\hline & $\begin{array}{l}\text { - “Para garantir a transparência da gestão e dos negócios, em benefício de todos os acionistas } \\
\text { e investidores, a Companhia conta com uma política de divulgação de informações, a qual } \\
\text { estabelece regras e procedimentos para pes soas vinculadas à Companhia (executivos e } \\
\text { empregados) com aces so a informações e fatos relevantes, e define os critérios, o momento e o } \\
\text { responsável pela divulgação de tais informações aos investidores, para garantir que os dados } \\
\text { para o mercado sejam dis tribuídos de forma ampla, transparente e homogênea.” } \\
\text { - “O EBITDA ajustado de Metais Básicos foi de R\$ } 6,8 \text { bilhões em } 2017 \text {, ficando } 8 \% \text { acima dos } \\
\text { R\$ } 6,3 \text { bilhões regis trados em } 2016 \text {, principalmente devido aos maiores preços (R } 3,3 \text { bilhões), } \\
\text { que foramparcialmente compensados por maiores custos e despesas (R } 1,2 \text { bilhão), pelo } \\
\text { impacto da variação cambial (R } \$ 870 \text { milhões) e por menores volumes (R\$ } 648 \text { milhões), } \\
\text { marcando } 2017 \text { como um ano de transição para um fluxo operacional mais simples no Canadá } \\
\text { que resultará em melhores margens a partir de } 2018 . ”\end{array}$ \\
\hline & $\begin{array}{l}\text { - "Passo a passo, reforçando a nos sa prospecção, incrementando o seu embasamento } \\
\text { analítico, fortalecendo a governança e a validação in-loco de todos os pontos analisados, } \\
\text { aprimorando os proces sos de legalização e de engenharia, regularizando o ritmo de aberturas } \\
\text { ao longo do ano, formando ainda mais gerentes por meio de um plano de carreira fortalecido e } \\
\text { passando a medir e prever canibalização e vendas marginais, conseguimos acelerar para cerca } \\
\text { de } 130 \text { novas lojas em } 2013 \text { e } 2014 \text {, para } 156 \text { lojas em } 2015 \text { e para em torno de } 210 \text { novas lojas em } \\
2016 \text { e } 2017 \text {, que totalizaram } 1.040 \text { novas aberturas." }\end{array}$ \\
\hline & $\begin{array}{l}\text { Negativas duplas: } \\
\text { - "Em todas essas ações, há prioridade não apenas em promover a proatividade das } \\
\text { comunidades, mas também em compartilhar valores tais como as melhores práticas sociais e a } \\
\text { transparência." }\end{array}$ \\
\hline & $\begin{array}{l}\text { Voz Passiva: } \\
\text { - "Agradecemos aos nossos colaboradores pelo empenho e talento que nos permitem obter } \\
\text { resultados consistentes, e aos nossos clientes e acionistas pela confiança que nos é } \\
\text { depositada." }\end{array}$ \\
\hline
\end{tabular}

